\title{
III-V-on-silicon Photonic Integrated Circuits for Spectroscopic Sensing in the Mid-Infrared
}

\author{
Gunther Roelkens $^{1,2}$ Ruijun Wang ${ }^{1,2}$, Anton Vasiliev ${ }^{1,2}$, Sanja Radosavljevic ${ }^{1,2}$, Fabio Pavanello ${ }^{1,2}$, Aditya \\ Malik $^{1,2}$, Muhammad Muneeb ${ }^{1,2}$, Roel Baets ${ }^{1,2}$, Stephan Sprengel ${ }^{3}$, Gerhard Boehm ${ }^{3}$, Markus-Christian \\ Amann $^{3}$, Ieva Šmonyte் ${ }^{4}$, Augustinas Vizbaras ${ }^{4}$, Kristijonas Vizbaras ${ }^{4}$ \\ ${ }^{1}$ Photonics Research Group, Ghent University-imec, Technologiepark-Zwijnaarde 15, 9052 Ghent, Belgium \\ ${ }^{2}$ Center for Nano- and Biophotonics (NB-Photonics), Ghent University, Ghent, Belgium \\ ${ }^{3}$ Walter Schottky Institut, Technische Universität München, Am Coulombwall 4, 85748 Garching, Germany \\ ${ }^{4}$ Brolis Semiconductors UAB, Moletu pl. 73, LT-14259, Vilnius, Lithuania \\ Authore-mail address: Gunther.Roelkens@UGent.be
}

\begin{abstract}
We present an overview of our work on mid-infrared photonic integrated circuits comprising silicon photonic ICs for the passive functionality and heterogeneously integrated III-V semiconductor devices for light generation and detection.

OCIS codes: (130.7408) Wavelength filtering devices; (130.3120) Integrated optics devices; (130.3060) Infrared
\end{abstract}

\section{Summary}

III-V/silicon photonic integrated circuits (ICs) promise to enable low cost and miniature optical sensors for trace-gas detection, bio-sensing and environmental monitoring. A lot of these applications can benefit from the availability of photonic ICs beyond the telecommunication wavelength range. Silicon-on-insulator (SOI) waveguide circuits allow operation up to about $4 \mu \mathrm{m}$ wavelength. Combined with suitable III-V semiconductors (InP type-II active regions or GaSb-based opto-electronic components) highly integrated systems-on-a-chip in the $2-4 \mu \mathrm{m}$ wavelength range can be realized. Beyond $4 \mu \mathrm{m}$ wavelength alternative CMOS-compatible waveguide platforms need to be considered, such as germanium-on-SOI. In this paper we will present $2 \mu \mathrm{m}$-wavelength-range III-V/silicon photonic ICs consisting of tunable laser sources, photodetectors and silicon waveguide circuits. Active opto-electronic components are integrated on the photonic IC by the heterogeneous integration of an InP-based type-II epitaxial layer stack on silicon. III-V-on-silicon $2.3 \mu \mathrm{m}$ range distributed feedback (DFB) lasers operate up to $25{ }^{\circ} \mathrm{C}$ in continuous-wave regime and shows an output power of $3 \mathrm{~mW}$. By varying the silicon grating pitch, a DFB laser array with broad wavelength coverage from $2.28 \mu \mathrm{m}$ to $2.43 \mu \mathrm{m}$ is achieved [1]. III-V-on-silicon photodetectors with the same epitaxial layer stack exhibit a responsivity of $1.6 \mathrm{~A} / \mathrm{W}$ near $2.35 \mu \mathrm{m}$. Integrated spectrometers based on silicon arrayed waveguide gratings and integrated photodetector arrays [2] and single pixel detectors [3] are demonstrated. In addition, we also report a $2 \mu \mathrm{m}$ range $\mathrm{GaSb} / \mathrm{silicon}$ hybrid external cavity laser using a silicon photonic IC for wavelength selective feedback. A wavelength tuning over $58 \mathrm{~nm}$ and side mode suppression ratio better than $60 \mathrm{~dB}$ is demonstrated [4]. For the $3 \mu \mathrm{m}$ wavelength we demonstrate the realization of high-performance arrayed waveguide gratings [5] and integrated spectrometers based on GaSb-based p-i-n photodetectors heterogeneously integrated on the silicon waveguide platform [6]. Beyond $4 \mu \mathrm{m}$ wavelength we propose the use of germanium on silicon-on-insulator waveguide circuits. We demonstrate high efficiency grating couplers [7], thermooptic heaters [8] and widely tunable Vernier ring resonator filters [9] on this platform in the $5 \mu \mathrm{m}$ wavelength range. Such circuits can then be integrated with III-V semiconductor quantum cascade or interband cascade gain chips to realize miniaturized widely tunable lasers.

\section{References}

[1] R. Wang, S. Sprengel, G. Boehm, R. Baets, M.-C. Amann, G. Roelkens, Broad wavelength coverage $2.3 \mu \mathrm{m}$ III-V-on-silicon DFB laser array, Optica, 4(8), p.972-975 (2017).

[2] R. Wang, M. Muneeb, Stephan Sprengel, Gerhard Boehm, A. Malik, R. Baets, Markus-Christian Amann3, G. Roelkens, III-V-on-silicon 2$\mu \mathrm{m}$-wavelength-range wavelength demultiplexers with heterogeneously integrated InP-based type-II photodetectors, Optics Express, 24(8), p.8480 (2016).

[3] R. Baets, D. Delbeke, G. Roelkens, W. Bogaerts, “Integrated spectrometers with single pixel detector,” WO Patent 2015/162197 (2015).

[4] R. Wang, A. Malik, I. Šimonytė, A. Vizbaras, K. Vizbaras, G. Roelkens, Compact GaSb/silicon-on-insulator 2.0x $\mu$ m widely tunable external cavity lasers, Optics Express, 24(25), p.28977 (2016). 
[5] A. Vasiliev, M. Muneeb, R. Baets, G. Roelkens, High Resolution Silicon-on-Insulator Mid-Infrared Spectrometers operating at 3.3 um, IEEE Photonics Society Summer Topicals 2017, Puerto Rico, p.177-178 (2017)

[6] M. Muneeb, A. Vasiliev, A. Ruocco, A. Malik, H. Chen, M. Nedeljkovic, J. S. Penades, L. Cerutti, J.B. Rodriguez, G. Mashanovich, M. Smit, E. Tournie, G. Roelkens, III-V-on-silicon integrated micro-spectrometer for the 3 um wavelength range, Optics Express, 24(9), p.9465-

$9472(2016)$.

[7] S. Radosavljevic, B. Kuyken, G. Roelkens, Efficient 5.2 um wavelength fiber-to-chip grating couplers for the Ge-on-Si and Ge-on-SOI midinfrared waveguide platform, Optics Express, 25(16), p.19034 - 19043 (2017).

[8] A. Malik, S. Dwivedi, L. Van Landschoot, M. Muneeb, Y. Shimura, G. Lepage, J. Van Campenhout, W. Vanherle, T. Van Opstal, R. Loo, G. Roelkens, Ge-on-Si and Ge-on-SOI thermo-optic phase shifters for the mid-infrared, Optics Express, 22(23), p.28479-28488 (2014).

[9] S. Radosavljevic, N. Teigell Beneitez, A. Katumba, M. Muneeb, M. Vanslembrouck, B. Kuyken, G. Roelkens, A Widely Tunable Vernier Filter on a Ge-on-SOI Platform for Sensing Applications, submitted for publication in Conference on Lasers and Electro-Optics, (submitted). 